\title{
Collaboration among vocational rehabilitation and mental health leaders: Supporting the vocational success of transition-age youth with serious mental health conditions
}

\author{
Anwyn Gatesy-Davis ${ }^{\mathrm{a}, *}$, Nancy Koroloff ${ }^{\mathrm{b}}$, Joseph Marrone ${ }^{\mathrm{c}}$ and Maryann Davis ${ }^{\mathrm{a}}$ \\ ${ }^{a}$ Transitions to Adulthood Center for Research, Implementation Science and Practice Advances Research Center, \\ Department of Psychiatry, University of Massachusetts Medical School, Worcester, MA, USA \\ ${ }^{\mathrm{b}}$ Regional Research Institute for Human Services, Portland State University, Portland, OR, USA \\ ${ }^{\mathrm{c}}$ Institute for Community Inclusion, University of Massachusetts, Boston, MA, USA
}

Received 29 June 2021

Revised 25 August 2021

Accepted 19 November 2021

Pre-press 21 February 2022

Published 23 March 2022

\begin{abstract}
.
BACKGROUND: The ability of vocational rehabilitation, adult mental health and child mental health service systems to collaborate regarding the employment and career development goals of transition-age youth has not been explored nor has attention been paid to strategies that would increase this collaboration.

OBJECTIVE: This qualitative study asks leaders from these three systems to describe collaborative activities that support better vocational services for transition-age youth with serious mental health conditions and discuss barriers and facilitators to collaboration.

METHODS: Qualitative interviews were conducted with 39 formal and informal leaders in vocational rehabilitation $(n=16)$, child mental health $(n=13)$, and adult mental health $(n=10)$ systems as part of a larger study of interorganizational relationships.

RESULTS: A primary barrier was lack of knowledge about the services and policies of each other's systems. Another barrier was differences in philosophy about employment and the special needs of transition-age youth with mental health needs.

CONCLUSIONS: In addition to specific activities that would encourage greater interaction across three systems, results underscore the need for the child mental health system and vocational rehabilitation system to increase their involvement with and knowledge about one another. This would include training child mental health providers about employment and career development services, vocational rehabilitation providers about the role of mental health in the youngest workers, and both being involved in transition-planning that directly addresses vocational goals and support needs.
\end{abstract}

Keywords: Transition-age youth, mental health services, vocational rehabilitation services, collaboration

*Address for correspondence: Anwyn Gatesy-Davis, Box 1821, Brown University, Providence, RI 02912-1821, USA; E-mail: anwyn_gatesy-davis@brown.edu. 


\section{Introduction}

Youth with a disability achieve competitive employment after high school at lower rates than that of young people without a disability. In 1995, postsecondary youth with serious mental health conditions had lower rates of employment than the general population of the same age and were less likely to be employed three to five years after high school than young people with any other type of disability (Wagner, 1995). Wagner updated those estimates in 2009 with data from a comparable sample who were 21-25 years old when interviewed. She found that the rate of high school completion for those with serious mental health conditions had improved; however, the rate of postsecondary education enrollment was just half the rate of the general population. Their point-in-time rate of post high school employment was significantly lower than that in young adults in the general population (Wagner \& Newman, 2012). Unfortunately, there is no research available to describe national rates of employment or postsecondary education for those with mental health disabilities since the Great Recession.

\subsection{Vocational outcomes}

The cost of the failure to transition to employment is great. A third of individuals receiving Supplemental Security Income (SSI) under age 65 are young adults, and $24 \%$ of those young adults have psychiatric disabilities (Social Security Administration, 2013). Receiving Social Security benefits is a strong disincentive to work (Becker et al., 2014; Burns et al., 2007; Frey et al., 2011). One study found that when youth with serious mental health conditions enroll in SSI before the age of 18 , they remain on the disability rolls for an average of 27 years (Rupp \& Scott, 1996). Conversely, young adults with serious mental health conditions who gain a foothold in the labor market are more likely to forestall entry into the disability system (Cougnard et al., 2007; Drake et al., 2013). Moreover, the earnings gaps between those with Bachelor's degrees and those with only a high school diploma or certificate has roughly doubled since 1980 (Autor, 2010; Autor et al., 2008), and wages increased substantially with even some college, or a postsecondary certificate or associates degree over those without any postsecondary education or training (Holzer \& Dunlop, 2013). Findings from the National Longitudinal Transition Study-2 further confirms the importance of services that support postsecondary educational and vocational goals for young adults with disabilities (Newman et al., 2011).

\subsection{Role of vocational rehabilitation services}

For working-age individuals with disabilities, the state vocational rehabilitation authority has responsibility for helping those with disabilities, including mental health disabilities, achieve employment and economic self-sufficiency. Recent federal legislation, the Workforce Innovation and Opportunity Act (WIOA; P.L. 113-128), has explicitly mandated that state vocational rehabilitation agencies provide specific services to better launch the adult employment of youth with disabilities. WIOA also gives special consideration to "high risk" youth, including those that have dropped out of school, are homeless, are involved with juvenile or criminal justice systems, are in or have aged out of foster care, and those who are pregnant or parenting (Miller et al., n.d.). For students with disabilities, WIOA sets forth the expectation that state vocational rehabilitation agencies will help with transition-related activities by providing Pre-Employment Transition Services to students of an age to receive transition planning (usually 14-21 year-olds, as defined in the Individuals with Disabilities Education Act) who are eligible or potentially eligible for vocational rehabilitation. This includes those who have not applied or been determined eligible for vocational rehabilitation services. The law also requires vocational rehabilitation agencies to commit a minimum proportion of federal funding that they receive to Pre-Employment Transition Services for students with disabilities (15\%), and 50\% of their supported employment program allotment for provision of Supported Employment services to youth (ages 14-24) with the most significant disabilities. Importantly, too, WIOA extends the previous 18-month limitation that an individual could receive supported employment services before the transition to on-going support, to a maximum of 24 months. These provisions make vocational rehabilitation systems an important resource for youth with serious mental health conditions.

Referral for vocational rehabilitation services typically happens for students who receive services under the Individuals with Disabilities Education Act during their Individualized Education Program's (IEP) mandated transition planning. However, less than $10 \%$ of students with serious mental health conditions are identified or qualified for an IEP (Forness et al., 2012), and a high proportion have dropped out of 
school before transition planning activities are completed (Wagner \& Newman, 2012). For this reason, schools are an insufficient conduit to the WIOAmandated vocational rehabilitation services for youth and students with serious mental health conditions. Given the changes introduced by WIOA, it is critical that collaboration among vocational rehabilitation service providers and mental health service providers be strengthened in a way that better supports young people with serious mental health conditions.

\subsection{Impact of cross-system collaboration}

While there is a growing literature on interventions that improve employment in youth and young adults with serious mental health conditions (e.g. Bond et al., 2016; Davis et al., 2018; Ellison et al., 2019), little is known about how vocational rehabilitation and mental health systems improve or impede employment and early career services for this population. One service system feature that holds promise is cross-system collaboration. Collaboration involves information exchange, activity modification, resource sharing, and building mutual capacity for reciprocal benefit and to achieve shared goals (Himmelman, 2001). Cross-system collaboration occurs among service providers from different systems and among defined units across service systems. Collaboration levels can be observed in whole systems, such as can be measured with Social Network Analysis (Milward et al., 2010; Morrissey et al., 1994; Nicaise et al., 2013) in which collaborative behaviors such as making or receiving referrals or meeting together for client planning purposes, is measured between each pair of organizations within the systems being observed (i.e. the network). This yields a measure of the interconnectedness of the entire network, as well as other measures, such as the proportion of linkages across, rather than within, specific systems (Davis, et al., 2018). Cross-system collaboration can also be observed at different levels of systems, for example within interagency teams whose charge it is to work together to address some shared goal. Team-based collaboration is typically measured using self-report measures completed by team members.

Some studies have found cross-system system collaboration can improve client-level outcomes, (e.g., Archer et al., 2012; Rosenheck et al., 2002) while others have not (Goldman et al., 2002). Of particular interest is one study (Fabian et al., 2016) that examined the impact of collaboration within interagency oversight teams on vocational outcomes in youth with disabilities served in the vocational rehabilitation system. They found that higher self-rated collaboration scores among interagency teams predicted a significant increase in the rate of successful employment outcomes of youth served in that team's geographic area when their cases were closed by their vocational counselor. Yet, a different aspect of team functioning, one that measured team cohesion or synergy, did not yield a positive outcome. These studies underscore the complexity of collaboration and the challenge of good measurement (Longoria, 2005). While findings on the relationship between cross-system collaboration and individual outcomes is mixed, there is, however, a consistent relationship between collaboration and increased service utilization (e.g., Rosenheck et al., 1998; Rothbard et al., 2004). For example, He and colleagues (2015) reported on a systematic intervention to increase collaboration between child welfare and mental health services which resulted in more screenings for mental health needs and an eight-year increase from $21 \%$ to $51 \%$ of children in the child welfare system receiving mental health services. Interorganizational collaboration (i.e. collaboration between organizations, not necessarily cross-systems) can also benefit organizations. It builds organizational capacity and leverages existing resources (Gray, 1989; Huxham, 1996) and is seen as increasingly necessary for solving complex problems (Trickett et al., 2011). Thus, given the benefits of cross-system collaboration, understanding the factors that lead to and support collaboration between vocational rehabilitation and mental health systems that serve transition-age youth should yield strategies for increasing that collaboration.

\subsection{Factors that impact collaboration}

Having a greater understanding of malleable organizational factors (i.e. that are amenable to change), that are associated with improved cross-system or interorganizational collaboration is critical to identifying or developing potential actions that will improve collaboration. Davis and colleagues used social network analysis to measure collaboration between programs serving either primarily youth or primarily adult age groups (Davis, et al., 2018). They found that programs that thought their important stakeholders (e.g. system leaders, funders) wanted greater collaboration across child-adult programs did in fact collaborate more with programs that served "the other" age group. Similarly, when important stakeholders promote collaboration (e.g. clear 
communication of expectations, removing barriers to collaboration) cross-system collaborative behavior increases (Nowell, 2009; Swanson et al., 2014). Various aspects of organizational complementarity (e.g. having complementary goals and services, a shared vision, low competition) facilitate interorganizational collaboration (Tsasis, 2009) as does organizations being knowledgeable about each (Hodges et al., 1998; Enemark et al., 2014).

There have been several studies that have examined collaboration between vocational rehabilitation and adult mental health at different levels of the systems. As early as 1995, Weinstock and Barker conducted an in-depth study of nine vocational rehabilitation programs, focused on their case management activities regarding those with psychiatric disabilities. They used a purposive sampling methodology to identify the programs and conducted structured interviews with those in various roles in the agencies as well as referring agencies. Six programs were selected for analysis regarding factors that enhanced collaboration between the agencies and adult mental health systems. They found that although funding limitations were a barrier, cooperative funding agreements, and mental health programs establishing themselves as an employment vendor for vocational rehabilitation facilitated collaboration. They also identified a number of ways that the design of services increased collaboration such as redefining traditional staff roles, co-location, and hiring staff with training and experience in both systems. Another study, conducted in England (Holwerda et al., 2016) examined the perceptions of mental health professionals and social security professionals about interdisciplinary collaboration. They found that when professionals collaborated in a structured way, (e.g. regular meetings) they were more positive about collaboration than when they collaborated in an ad hoc manner. Lastly, Noonan and colleagues (2012) investigated the role of the state level interagency team in improving collaborative behavior. They examined a state interagency team comprised of members from 10 state agencies including the Department of Mental Health and the Department of Vocational Rehabilitation. Through Social Network Analysis of individuals on the team they identified an increase in connections between team members over time. Their focus group results yielded two main themes, collaborative capacities and collaborative strategies. Collaborative capacities refer to processes or characteristics internal to the group that support successful functioning. These included having a variety of partnerships, relationships, time together, shared vision and shared leadership. Collaborative strategies refer to activities of the group that support successful functioning. These included site visits, joint planning, joint training and sharing information. Taken together, these studies have identified a variety of factors that can enhance collaboration between vocational rehabilitation and adult mental health systems.

Little is known about collaboration between vocational rehabilitation and mental health systems serving transition-age youth. Transition-age youth are served in both the child and adult mental health systems because their ages span adolescence and young adulthood. The impact of WIOA calls for a better understanding of how to enhance collaboration within this triangle of systems (i.e. vocational rehabilitation, adult mental health, child mental health). Service providers, family members and transitionage youth themselves need better tools and methods for identifying resources that can aid career and employment goals development and planning the steps to achieve those goals. This qualitative study asks leaders from these three service arenas to describe their collaborative activities with each other regarding this population and their vocational support needs and to discuss factors that would help increase that collaboration. The goal of this study was to better understand factors that facilitate or hinder their collaboration. In line with stages of early investigation of a phenomenon, we used qualitative interviewing to obtain rich data from which principles or themes could be discovered.

\section{Materials and methods}

The qualitative interview data reported in this article came from a larger study of relationships among vocational rehabilitation and mental health systems which included a social network analysis conducted by web survey and analysis of relevant RSA data. All methods for this study were approved by the institutional review board of the University of Massachusetts (approval \# H00008656, on 9/8/2015). The data were collected from communities that were included in the 16 grants from the Substance Abuse and Mental Health Services Administration "Now is the Time - Healthy Transitions" program. Grantees received funding from 2014 to 2019 and were expected to improve services for youth and young adults with, or at risk of, serious mental health conditions in at least two communities 
in the grantee state. In the communities served by the grantees, key informants were identified by contacting the local publicly funded branch of the state vocational rehabilitation department and the local entities most identified to carry out state and federal mandates for child mental health and adult mental health. The regional administrator for vocational rehabilitation, child mental health and adult mental health were identified as key informants to participate in the study. Potential participants were recruited via letter and e-mail, inviting them to participate in an interview. In some cases the regional administrator delegated a program manager or direct services provider to respond. We refer to interviewees as "leaders" throughout this article because all were knowledgeable about services for youth and young adults with disabilities, even though some did not hold administrative positions. Follow-up phone calls or e-mails were used to set up hour-long phone interviews with participants. Participants were offered a \$25 gift card for participating: however, most participants declined the gift card because of organizational policy about accepting gifts. Interview questions were provided to participants prior to the interview so that they had sufficient time to prepare. Participants were asked to respond based on their professional experience and were not expected to represent the views of their employer.

The interview guide was constructed by the researchers including one with prior experience working in mental health and vocational rehabilitation systems, as well as extensive research expertise in these systems nationally. Because each interview was selected based on their position in the service system, demographic information were not considered relevant. The interview guide explored the concept of collaboration defined as "actively working together to achieve shared goals for the vocational outcomes of 16-26-year-olds with psychiatric disabilities." Respondents were asked questions such as the following: Would you describe how your local [VR,AMH,CMH] system delivers services for transition age youth and young adults with psychiatric disabilities; What do you view as desirable collaboration in order to improve employment and educational outcomes between [insert their system] and [other two systems]; What do you see as barriers to collaboration that should improve employment and educational outcomes; What do you see as facilitators to collaboration that should improve employment and educational outcomes? The following research question was employed to structure both the interview schedule and the qualitative data analysis: What efforts are local vocational rehabilitation/child mental health/adult mental health systems making to build infrastructure for youth and young adults with serious mental health conditions via cross-triangle collaborations?

Researchers successfully conducted at least one interview with informants in 20 of the 31 potential communities $(64.5 \%)$, collecting data from 39 of the $93(42 \%)$ informants invited to participate. The researchers conducted interviews with 16 leaders from vocational rehabilitation, 10 leaders from adult mental health, and 13 child mental health leaders. The leaders were asked about collaboration between their system and the other two systems in the triangle. Interviews were transcribed and each transcript was coded by at least two members of the research team. Initial coding followed the lines of the interview questions and yielded several major themes. Within these major themes, a second level of analysis was conducted to identify specific quotations that expanded on the relationship between mental health and vocational rehabilitation systems and their perception of collaboration. A measurement of intercoder reliability was computed yielding $90 \%$ agreement and a Cohen's Kappa value of 0.78 which is at the high end of the moderate category (McHugh, 2012).

\section{Results}

Responses to questions about the nature of the collaboration between systems were the main source of discovered themes about collaboration; however, questions that were not explicitly about collaboration sometimes yielded comments that described collaborative efforts, and those excerpts were included in the analysis. Evidence of active collaboration was limited, in general. There was collaboration between vocational rehabilitation and adult mental health, mostly around mental health clients older than transition- age youth. There were few examples of collaboration between child mental health and vocational rehabilitation. Coordination between vocational rehabilitation and schools was mentioned frequently by respondents from vocational rehabilitation even though no questions specific to this collaboration were asked.

\subsection{Facilitators to collaboration}

Facilitators to collaboration were defined for respondents as activities or conditions that lead to 
greater connection among the systems and support the employment and educational outcomes of youth and young adults with psychiatric disabilities. In general, opportunities for staff to build relationships across agencies and learn more about other agencies were seen as facilitators to cross-triangle collaboration. A variety of occasions can create these opportunities to get to know each other. Participants identified meetings across agencies, referrals, shared/cross training of staff, and working toward a common goal as situations that facilitated collaboration.

\subsubsection{Meetings}

Participants noted that meetings between crosstriangle agencies create individual relationships between staff and offer staff a chance to gain information about each other's agencies.

“... knowing key people... that's where it's helped with our regional interagency councils ... Everybody there knows somebody to call. If they don't know the answer, they'll say 'You know, you really need to call downtown to so and so at Voc. Rehab." (child mental health)

"We have \{vocational rehabilitation $\}$ staff designated to work with our providers...They go on site with our providers to give them an understanding of who they are, what they are, what they do, what their strengths and weaknesses are. And then they meet regularly with our staff ... to review where we are and we address issues proactively." (adult mental health).

"There was a suggestion by our chief psychiatrist ... that maybe we do some reach out. So the three regional directors [of vocational rehabilitation] and the director from [state department of mental health] went and met with the regional directors of the child mental health side. We did... Voc Rehab 101 and talked about WIOA and the changes... We learned more about the services that they provide. Because it really is two different systems at [department of mental health]... the child and adolescent system and the adult system.” (vocational rehabilitation).

\subsubsection{Referrals}

Referrals act as a mechanism to transfer young people from one agency to another and can build relationships between the referring staff.
"And we're very lucky. [vocational rehabilitation] is not only in the same building as us. They're across the hall... we have immediate access to them ... I have meetings with them on a quarterly basis where we talk about barriers, about difficult situations ... ways to promote referrals to [vocational rehabilitation]". (adult mental health)

“... we have longstanding relationships with [vocational rehabilitation] ... And in fact, one of our youth and young adult case managers that was with us for many years left and took a job there. And so she's been a really great link for us ... She sends people to us. We send people to her." (adult mental health)

“... something we do...in working with their transition plans is identifying their goals, and who do we need at the table? So if that's someone from Voc. Rehab. then that person from Voc. Rehab. will be invited to come there to attend that meeting. And help explain what type of services they can provide for the youth and it's kind of like a warm linkage. And now they're part of the team." (child mental health)

"We have a really robust IPS service in the district... and there's excellent coordination between those and our agency. But the adolescent program doesn't really coordinate with us at all". (vocational rehabilitation)

\subsubsection{Shared/Cross training}

Another opportunity to build relationships with staff from other agencies is found in the form of crossagency staff trainings. This theme primarily appeared in interviews with leaders in the adult mental health system and less frequently in interviews with vocational rehabilitation participants.

"Yes, we're working with [vocational rehabilitation] very aggressively to try to get a lot of our providers trained in employment services so they understand how to work with and intervene, and also understand what services are available to the individual, who is impaired." (adult mental health)

"And then we do open up our trainings to each other. So [department of mental health] will send us their training, even if they are external to the agency. We do the same. A lot of planning is involved in this." (vocational rehabilitation) 


\subsubsection{Concrete projects build collaboration}

Working toward a shared goal involves communication and forging working relationships across agencies. One example of a concrete project that brings these three systems together recently was planning for services prescribed by WIOA.

"We work with them [vocational rehabilitation] around the type of technical assistance we need [from WIOA]. And we were able ... to select our provider... We are at the table helping to craft the initiative and to implement the initiative... We're equal partners." (adult mental health)

“... which is really exciting and sort of new at this point, is something the [state] received from SAMHSA. It's called a Healthy Transitions Grant ... As a part of that grant, we have, through collaborative effort, had a drop-in center... Its sort of a morph between a drop-in center and a clubhouse that is open in [community]." (vocational rehabilitation)

"Mental health, vocational rehabilitation and Developmental Disabilities have all kicked in additional money to have more benefit specialists available. And we're making a real effort to get that information to transition youth. So for example [staff] did a presentation at the special education director's conference recently... so they have an understanding of how benefits would be impacted by youth going to work." (vocational rehabilitation)

\subsection{Barriers to collaboration}

For this study, those conditions, attitudes or activities that served to hinder collaboration among the three systems were considered challenges or barriers to collaboration. Some challenges stem from different levels of information or differing perspectives, while others were based in conflicting service philosophies or logistics among the three groups.

\subsubsection{Familiarity/Relationship between agencies}

One barrier to interagency collaboration is a lack of basic knowledge about services, policies, and work culture across the three systems. Adult mental health often refers clients to vocational rehabilitation for employment services, thereby creating an opportunity for communication between those two agencies.
Interviews suggest that there is less opportunity for interaction between vocational rehabilitation and child mental health, thus creating fewer opportunities for working relationships. In the interviews, participants from vocational rehabilitation indicated that their agency is relatively unknown to child mental health and interviews with participants from child mental health suggest they do not see it as their role to interface with vocational rehabilitation.

"In terms of the overall system, I don't think we're there yet. I think that we need to-you know I think the first thing that we need to do is we all just need to sit down and talk and say Okay, what are you seeing? What are we seeing? How can we do this better than we're doing it right now?" (vocational rehabilitation)

“... we work closely with the [vocational staff at mental health], but she's working mostly with adults. So the kid's population is not really-you know we don't necessarily have a direct link to that right now, you know ... We don't have real direct line."(vocational rehabilitation)

Child mental health also noted a barrier between their agency and vocational rehabilitation. The lack of communication prevents these two agencies from forming even a casual relationship that might foster a collaboration in the future.

“... I don't know how to start a referral to vocational rehabilitation. So what does that tell you?" (child mental health)

"But you know when I talk to people about vocational rehabilitation, most of our staff don't relate to that, because they're not really working with them." (child mental health)

While adult mental health is more likely to encounter situations that put them in the same room as vocational rehabilitation, that does not mean that the two agencies have strong ties. As adult mental health participants pointed out, a lack of knowledge about the services offered by each agency still acts as a barrier to potential collaboration.

“... But I do think it would be really important to continue even beyond an MOU or before an MOU, really doing some concerted efforts between the two organizations to educate more and more frontline staff around who does what and who can do what..." (adult mental health) 


\subsubsection{Readiness to work}

Readiness to work is a topic that came up frequently in interviews with vocational rehabilitation staff. The three systems do not always see eye to eye on what "readiness" looks like, particularly for young people with serious mental health conditions. Conflicting ideas about when a young person is ready for vocational rehabilitation service acts as a barrier to collaboration.

"I think there's a disconnect with understanding exactly what we do... I always feel like nobody thinks somebody with a particularly mental health issue can work, so they don't refer them. They don't avail themselves of the services." (vocational rehabilitation)

"And [lets] get rid of the myth that people have to be absolutely ready for employment. We prepare people for that. Obviously someone doesn't need to be ready to go off to work tomorrow. But they do need to be ready to engage [with us] ..." (vocational rehabilitation)

“... there is an issue about whether people feel that if somebody's got a severe and persistent mental illness whether they're going to be ... able to work. So trying to get people more accustomed to thinking about those things for that population as well is kind of the work that we have to do." (child mental health)

"I think we're constantly working with our providers around not having just an illness hopeless mindset." (child mental health)

\subsubsection{Special needs of youth of transition age}

Transition-age youth with serious mental health conditions are a unique population that can be served by all three systems. In the past 10 years, mental health service systems have become aware that the needs of transition aged youth are different than the needs of children or older adults. As a result of WIOA, vocational rehabilitation systems are increasingly aware of the nature of the needs for transition-age youth, but these are relatively new practices that may not have produced widespread understanding. From the perspective of mental health leaders, vocational rehabilitation providers had little understanding of either the age group or the unique needs of those in this age group with serious mental health conditions. Participants from both mental health systems noted that vocational rehabilitation may not be prepared to serve this specific population.
“... [vocational rehabilitation] complain[s] about mental health disabilities versus physical disabilities, and not knowing how to work with them." (adult mental health)

"These programs need to be more flexible, and they seem to be rigid when it comes to the subset of adolescents with the high-end mental health needs." (child mental health)

"There's a disconnect between them [vocational rehabilitation] making their numbers and helping people who are more autonomous than those who need that extra... warm hand-holding." (child mental health)

Respondents from vocational rehabilitation spoke candidly about their own unpreparedness for working with youth with serious mental health conditions.

"And our counselors are sort of going, you know, help! We didn't really get into the field for-we thought we were serving adults. How do we serve this population because it is a different population in terms of getting them engaged?" (vocational rehabilitation)

"... I have the sneaking suspicion, and I have no proof, that I have the sneaking suspicion that maybe individuals who are seriously and persistently mentally ill don't make it as far in our system - that they're the individuals that don't get made eligible or don't get put into plans ..." (vocational rehabilitation)

"We have a workshop which has always been designed and geared towards adults. And it works for adults ... But when we try the same workshop with youth, by the second day, no one comes back. You know it's a real good indicator that we're not providing things to engage them." (vocational rehabilitation)

Additionally, a number of participants noted that vocational rehabilitation does not usually offer special programs for youth with serious mental health conditions.

"I'm not sure we have any specific programs specific for youth with psychiatric disabilities. But we have lots of programs. And we're doing lots of innovative things in the area of transition. So all students who are considered you know eligible for our services have a disability ... But I don't think we have any specific transition programs for specific disabilities." (vocational rehabilitation) 


\subsubsection{Adult mental health provides employment services}

Adult mental health has offered employment services for adults with mental illness either directly or through collaboration with vocational rehabilitation for the last several decades. Recently adult mental health employment services have begun to expand those programs to include special programs for transition age youth. This can allow adult mental health to support the employment goals of young people without referring them to vocational rehabilitation. In terms of interagency collaboration, decreasing the need for contact with another agency is a barrier to forming relationships and engaging in collaborative activities.

“... Why do we have to jump through the hoops of vocational rehabilitation... Why not cross-train us so that we can provide the exact same service that they provide? Why make it two different agencies that have to collaborate? Why not make it one position that can do both?" (adult mental health)

"There are a lot of different resources in different places that are not well connected to each other... because they go to mental health and get just that piece. And then mental health seeks out grants to keep adding more and more things, rather than looking at maybe someone else is providing that." (vocational rehabilitation)

\subsubsection{Timing of services}

One of the major barriers mentioned in interviews with mental health leaders was the difference between vocational rehabilitation and mental health regarding how fast a young person could be seen, assessed and services begun. Both adult mental health and child mental health noted that the case flow at vocational rehabilitation is much slower than that of the mental health system. This difference in timing has a significant impact on young people motivated to find employment.

"We use motivational interviewing and once they're in the action stage phase, we have about a five-day window... And [vocational rehabilitation] is on a five month window timeframe." (adult mental health)

“... And I've lost a couple just in the wait time. They were okay going and then they had to wait ... like a month. And they were like oh, I'm not interested right now. You have to get them in the moment." (adult mental health)

"We do work with vocational rehabilitation. But I find for this population, it's too full and too cumbersome. There are too many hoops to jump through. Too much paperwork and red tape." (child mental health)

\subsubsection{Limited resources}

As might be expected diminishing resources are a barrier for all systems, however, this was most frequently mentioned by interviewees from vocational rehabilitation. Lack of resources are often mentioned when interviewees described attempts to collaborate on specific projects. When one agency has-or is perceived as having- fewer resources to bring to the table, collaboration becomes more difficult.

“... So it's hard for our staff to kind of be everywhere at one time. But now ... if we had plenty of staff, and plenty of money to do things with, then eventually you know we could increase our footprint in these agencies. And we could have staff assigned to or be given a caseload with a focus on mental health." (vocational rehabilitation)

“... And we end up having situations where their funding, vocational rehabilitation funding, they may have exhausted it. So then you have to wait for the following fiscal year to even be able to refer people." (child mental health)

"I think ... people have the feeling of being overwhelmed and overworked in that they're overburdened and taxed." (adult mental health)

\subsubsection{The role of the schools}

In addition to working with each other, each of the three systems work with many other service systems and organizations. For youth and young adults, a primary example is the education system, which is recognized directly in federal vocational rehabilitation legislation and is expected to support transition planning for young people with disabilities. Participants from child mental health mentioned the role played by schools frequently in their interviews. Vocational rehabilitation works directly with the schools to connect young people with employment services however, this is usually limited to those young people with an IEP and who complete their high school diploma or certificate, or age out at 21 or 22 (depending on state policy). The federal Individuals with Disabilities Education Act leads vocational 
rehabilitation to collaborate with the education system rather than child mental health. Similarly, child mental health assumes that the schools are taking care of any referrals that need to be done and don't see collaboration with vocational rehabilitation as part of their role.

“... we don't really collaborate with the Vocational Rehabilitation system... We don't work directly with them... That would be really the school system... I don't even know that our regional teams work much with them." (child mental health)

"I don't know that this is a barrier so much. I mean I just don't think that we have seen this in our role. ... Because it's more the educational system's role. So I don't think we're really are doing much collaboration." (child mental health)

\section{Discussion}

This study asked leaders from the child mental health, adult mental health, and vocational rehabilitation systems in twenty communities about the how their systems collaborate with each other for the purpose of supporting the vocational goals of transition-age youth with serious mental health conditions, what helps them collaborate and what challenges they face to that collaboration. The focus of the research was on the relationship between the two mental health systems and vocational rehabilitation and did not look at collaboration between child and adult mental health. Respondents from all three service systems described both factors that facilitate and impede interagency collaboration. In general, respondents from the three systems were in agreement about facilitators of interagency collaboration, but diverged in their descriptions of the barriers. Child and adult mental health noted some of the same challenges in collaborating with vocational rehabilitation. Vocational rehabilitation, on the other hand, identified some obstacles unique to their perspective. These findings have implications for strategies that could change those factors that most likely to improve collaboration among the three systems.

Respondents from all three systems suggested that opportunities for staff to build relationships across agencies and learn more about other agencies would facilitate collaboration. They also indicated that these opportunities occurred infrequently. Some of the activities that were suggested to improve cross-system relationship and knowledge building are by some definitions (e.g., Morrissey et al., 1994) the very elements of collaboration, such as having shared meetings and making/receiving referrals. Findings from previous studies suggest that these opportunities will be more successful if they are structured (e.g. regular meetings) rather than ad hoc (Holwerda et al., 2016), include processes that support collaboration, such as having time together and developing a shared vision, and shared activities (Noonan et al., 2012). Much like the findings of Noonan and colleagues (2012), respondents indicated that another way to build cross-system relationships and knowledge is to organize concrete projects during which participants from multiple systems accomplish a shared goal. Examples included working on a grant proposal together, working together to develop implementation plans for new policy, or developing mechanisms for shared funding.

Leaders from all three systems agreed that vocational rehabilitation was not prepared for or knowledgeable about working with transition-age youth, and that this impeded collaboration. While implementation of WIOA may be rapidly changing this picture, it is worth noting that mental health systems have been trying to improve services for transition-age youth over the past two decades. Collaboration between these three systems might be enhanced by forums in which each ones' experiences and expertise in this age group are shared, particularly if it was tied to achieving a specific goal.

In contrast, their perspectives were different on the topic of addressing the specific needs of individuals with serious mental health conditions. Both child and adult mental health identified a lack of recognition in the vocational rehabilitation system of the special needs of this disability group as a barrier to their collaboration with vocational rehabilitation. Whereas vocational rehabilitation leaders described a perspective or philosophy that their services were for all disability groups, with the implication that special services for a particular group was not needed. This view may stem from their use of the Individual Plan for Employment (IPE) as a means to tailor services to each individual, and thus address any specific needs for individuals with mental health disabilities. These perspectives suggest that the two systems may benefit from forums in which these differing perspectives could be shared and support co-development of strategies to alleviate the concerns.

Another barrier shared by leaders from both mental health systems was that the delay between referral to 
vocational rehabilitation and the receipt of concrete employment services is an impediment to their clients and reduces collaboration with vocational rehabilitation. While leaders in vocational rehabilitation did not speak to the timing issue, they raised a separate - but potentially related - barrier. Vocational rehabilitation articulated some conflict in perceptions of readiness to work, and suggested that there is disagreement between mental health and vocational rehabilitation systems about what "readiness" looks like and whether mental health providers refer the right individuals at the right time. As long as leaders from mental health systems perceive that vocational rehabilitation services are not up to the task of serving transition-age youth with serious mental health conditions well, and vocational rehabilitation leaders perceive that mental health providers don't refer individuals when they are actually ready to work, these perceptions will likely remain a barrier to collaboration. Activities, such as cross-training, about vocational rehabilitation processes and appropriate referrals as well as the unique needs of transitionage youth for employment supports, followed by opportunities for continued dialogue about progress in collaborating to help this population, would likely help align perceptions and address underlying issues.

One of the most important issues that arose in these interviews came from an absence of recognition on the part of child mental health leaders of the value of collaborating with vocational rehabilitation. This was based on their assumption that it is schools that connect students directly to vocational rehabilitation services and as a consequence child mental health had little role or value in collaborating with vocational rehabilitation and have little need to learn about that system. As individuals from all three systems noted, many of the facilitators to collaboration involve situations and activities that put individuals from different agencies in contact so that they can build one-on-one relationships. If schools are the only route by which youth get to vocational rehabilitation services, it eliminates those opportunities for child mental health and vocational rehabilitation to form strong working relationships. However, there is, in fact, a great need for that relationship. Child mental health serves many youth who do not fit the pathways that schools employ to connect students with disabilities to vocational rehabilitation services. The school-to-vocational rehabilitation pathway has typically occurred through the transition planning that is mandated by the Individuals with Disabilities Education Act and applies to students with an
Individualized Education Plan. The Act requires transition plans for post school functioning, including work or postsecondary schooling and training, and identifying and connecting to the state agencies that will help fulfill those goals, including vocational rehabilitation services as appropriate. However, no transition planning is required for students not in special education, or youth who drop out of high school. As noted previously, only a small fraction of students with serious mental health conditions are in special education (Forness et al., 2012) and these students also drop out of high school at very high rates (Wagner \& Newman, 2012). Child mental health serves many of these youth who are off the typical pathway to vocational rehabilitation. Improving collaboration between the child mental health and vocational rehabilitation systems would particularly benefit this group of young people. The fact that child mental health leaders did not recognize that many of their clients were unlikely to be connected to vocational rehabilitation services through schools was concerning. This group of young people, many of whom are high risk and have very difficult transitions, are generally unrecognized, uncounted, and their needs don't get considered when systems collaborate and plan. The services that the Workforce Innovation and Opportunity Act mandates vocational rehabilitation systems to provide to students and youth with disabilities, regardless of their special education status, makes it particularly necessary for vocational rehabilitation and child mental health systems to connect around those students who are not in special education, and to develop and strengthen their collaboration.

\subsection{Limitations}

The results outlined in this study should be interpreted with several limitations in mind. First under $50 \%$ of those who were invited to participate were willing to schedule an interview. Because the individuals who did participate came from most of the communities involved in the 16 grantee areas, the researcher felt that the number of participants would yield useful data for a qualitative study. Second, the 16 areas had all received a competitive grant and although this does not necessarily require a positive relationship between mental health and vocational rehabilitation, the existence of such a relationship might make a proposal more competitive. Because the researchers were looking for positive examples of collaboration, this bias in selection seemed 
reasonable. Finally, in some cases, the interviewees from vocational rehabilitation were often regional managers and did not have detailed information about how vocational rehabilitation counselors who worked directly with young adults with mental health challenges practiced or what issues they might be facing. This lack of understanding of line level practice did not seem to be an issue with mental health respondents.

\subsubsection{Implications/Next steps}

When it comes to improving interagency collaboration, there is general agreement across these respondents that the first step is getting to know each other. Activities such as meetings, referrals, and cross- or shared trainings all offer opportunities for individuals get to know people from other agencies, what services they provide and how the system works. Putting faces to names and connecting on a personal level helps build the individual relationships that make interagency collaboration possible. Not only do people get to know each other, they learn more about other systems' policies and services. The lack of knowledge about other systems was often mentioned as a barrier to collaboration. While this issue could be addressed at any level, one way that individuals can gain more information is simply by talking to people from systems outside of their own. Such opportunities may need to be formally facilitated since it appears that they are not currently prevalent, particularly between child mental health and vocational rehabilitation. In addition to understanding each other's services better, service providers in all three systems might benefit from a greater understanding of transition to work and early career development, use of youth peer support, and ways to provide clinical support to youth and young adults who are working. Vocational rehabilitation staff might be interested in discussing ways of dealing with challenging youth behaviors and the role of brain development, conversations that could be facilitated by individuals from the child mental health system.

Another facilitator of collaboration is having a shared task or goal to work toward. In the case of our study, the planning for the newly passed (at the time of interviews) Workforce Innovation and Opportunity Act (WIOA) was recognized by many respondents as an example of how a common goal and shared task could lead to increased collaboration. The pressing needs of that population of young people with serious mental health conditions who are not in school or not in special education may present a common task that could bring all three systems to the table. If adult mental health, child mental health, and vocational rehabilitation can all recognize that this particular population is underserved, they may be able to work towards the common goal of improving services for youth outside of the school system. The recent WIOA legislation that allows vocational rehabilitation to provide group education and support to young people who have not completed vocational rehabilitation eligibility creates an opportunity for the three systems to work together to find ways to help more young people in these pre-employment workshops.

Another topic that might be tackled by providers from all three systems is brainstorming ways of modifying the traditional approach to IPE development used by vocational rehabilitation to incorporate a "work and career development" phase that allows for developmentally appropriate career exploration. A workgroup composed of members from each system could also develop service interventions for youth that use a greater variety of employment models, especially those based on experiential, work- based learning. The creation of models of vocational peer support that are appropriate for young adults and the development of ways to include family member strength and resources into the IPE planning would be another contribution to the knowledge base.

Individuals, such as those interviewed in this study, who occupy formal or informal leadership positions have an opportunity to increase interagency collaboration with their actions. The strategies discussed in the last two paragraphs, opportunities to get to know each other and working together on common tasks, are activities that are usually initiated and often facilitated by those in administrative positions. Earlier research (Davis et al., 2018) established that when programs perceived that important stakeholders such as their administrators and funders wanted more collaboration, then more collaboration happened. At a systems or policy level, the words and actions of those at the top are influential. Not only do leaders need to speak often and persuasively about collaboration and initiate activities that will promote collaboration, they also need to identify opportunities to change administrative rules and procedures that serve as barriers to participating in collaborative activities. A first step might be for leaders in mental health and vocational rehabilitation to require that at least a portion of their training budgets be spent on trainings that will bring these systems together. Another approach that leaders can use is the development of specific 
MOUs or agreements that are focused on the special needs of youth and young adults with mental health conditions.

\section{Conclusion}

Youth and young adults often find the journey into full adulthood difficult, made more so by society's expectations that that they become employed, find a career and generally be able to support themselves. The journey to adulthood is even harder for young adults with mental health challenges who must manage the symptoms created by their mental health condition while at the same time coping with a confusing and changing service system. It is clear that increasing collaboration among service systems improves services and it is critical to the health and long term well-being of young adults that we use the knowledge created by research to make these changes.

\section{Acknowledgments}

The authors thank the following individuals who were central to the success of this project: Lisa Smith, Amanda Costa, Raphael Mizrahi, Martha Castro, all of whom collected or analyzed data. They also thank Gwen White who helped them identify system leaders.

\section{Conflict of interest}

The authors declare that they have no conflict of interest.

\section{Ethical disclosure}

Ethical approval of this research was obtained from the University of Massachusetts Medical School's institutional review board (IRB Registration: 0000160; Approval \#H00008656).

\section{Informed consent}

Verbal informed consent to collect and publish the anonymized data was obtained from participants prior to the start of the qualitative interview.

\section{Funding}

This research was funded by a grant from the National Institute of Disability, Independent Living, and Rehabilitation Research (NIDILRR) of the Administration on Community Living (ACL) and the Center for Mental Health Services, of the Substance Abuse and Mental Health Services Administration (SAMHSA) of the U.S. Department of Health and Human Services (grant number 90RT5031). The content of this paper does not necessarily represent the policy of NIDILRR or SAMHSA, and you should not assume endorsement by the Federal Government.

\section{References}

Archer, J., Bower, P., Gilbody, S., Lovell, K., Richards, D., Gask, L., Dickens, C., \& Coventry, P. (2012). Collaborative care for depression and anxiety problems. The Cochrane Database of Systematic Reviews, 10, CD006525. https://doi.org/10.1002/ 14651858.CD006525.pub2.

Autor, D. H. (2010). The polarization of job opportunities in the US labor market: Implications for employment and earnings. Center for American Progress and The Hamilton Project, 6(25).

Autor, D. H., Katz, L. F., \& Kearney, M. S. (2008). Trends in U.S. Wage Inequality: Revising the Revisionists. Review of Economics and Statistics, 90(2), 300-323.

Becker, D. R., Drake, R. E., \& Bond, G. R. (2014). The IPS supported employment learning collaborative. Psychiatric Rehabilitation Journal, 37(2), 79-85. https://doi.org/10.1037/ prj0000044

Bond, G. R., Drake, R. E., \& Campbell, K. (2016). Effectiveness of individual placement and support supported employment for young adults. Early Intervention in Psychiatry, 10(4), 300-307. https://doi.org/10.1111/eip.12175

Burns, T., Catty, J., Becker, T., Drake, R. E., Fioritti, A., Knapp, M., Lauber, C., Rössler, W., Tomov, T., van Busschbach, J., White, S., Wiersma, D., \& EQOLISE Group. (2007). The effectiveness of supported employment for people with severe mental illness: A randomised controlled trial. Lancet (London, England), 370(9593), 1146-1152. https://doi.org/10.1016/ S0140-6736(07)61516-5

Cougnard, A., Goumilloux, R., Monello, F., \& Verdoux, H. (2007). Time between schizophrenia onset and first request for disability status in France and associated patient characteristics. Psychiatric Services (Washington, D.C.), 58(11), 1427-1432. https://doi.org/10.1176/ps.2007.58.11.1427

Davis, M., Koroloff, N., Sabella, K., \& Sarkis, M. (2018) Crossing the Age Divide: Cross-Age Collaboration Between Programs Serving Transition-Age Youth. Journal of Behavioral Health Services \& Research, 45(3), 356-369.

Davis, M., Sheidow, A. J., McCart, M. R., \& Perrault, R. T. (2018). Vocational coaches for justice-involved emerging adults. Psychiatric Rehabilitation Journal, 41(4), 266-276. https://doi.org/10.1037/prj0000323

Drake, R. E., Xie, H., Bond, G. R., McHugo, G. J., \& Caton, C. L. M. (2013). Early psychosis and employment. Schizophrenia 
Research, 146(1), 111-117. https://doi.org/10.1016/j.schres. 2013.02.012

Ellison, M. L., Huckabee, S. S., Stone, R. A., Sabella, K., \& Mullen, M. G. (2019). Career Services for Young Adults with Serious Mental Health Conditions: Innovations in the Field. The Journal of Behavioral Health Services \& Research, 46(1), 1-14. https://doi.org/10.1007/s11414-018-9638-3.

Enemark, D., McCubbins, M. D., \& Weller, N. (2014). Knowledge and networks: An experimental test of how network knowledge affects coordination. Social Networks, 36, 122-133. https://doi.org/10.1016/j.socnet.2012.10.001.

Fabian, E., Simonsen, M., Deschamps, A., Shengli Dong, \& Luecking, D. M. (2016). Service System Collaboration in Transition: An Empirical Exploration of its Effects on Rehabilitation Outcomes for Students with Disabilities. Journal of Rehabilitation, 82(3), 3-10.

Forness, S. R., Freeman, S. F. N., Paparella, T., Kauffman, J. M., \& Walker, H. M. (2012). Special Education Implications of Point and Cumulative Prevalence for Children With Emotional or Behavioral Disorders. Journal of Emotional and Behavioral Disorders, 20(1), 4-18. https://doi.org/10.1177/ 1063426611401624.

Frey, W., Drake, R., Bond, G., Miller, A., Goldman, H., Salkever, D., \& Holsenbeck, S. (2011). Mental Health Treatment Study: Final report. Social Security Administration. https:// www.ssa.gov/disabilityresearch/documents/MHTS_Final_ Report_508.pdf.

Goldman, H. H., Morrissey, J. P., Rosenheck, R. A., Cocozza, J., Blasinsky, M., \& Randolph, F. (2002). Lessons From the Evaluation of the ACCESS Program. Psychiatric Services, 53(8), 967-969. https://doi.org/10.1176/appi.ps.53.8.967.

Gray, B. (1989). Collaborating: Finding common ground for multiparty problems. Jossey-Bass.

He, A. S., Lim, C. S., Lecklitner, G., Olson, A., \& Traube, D. E. (2015). Interagency collaboration and identifying mental health needs in child welfare: Findings from Los Angeles County. Children and Youth Services Review, 53, 39-43. https://doi.org/10.1016/j.childyouth.2015.03.013.

Himmelman, A. T. (2001). On Coalitions and the Transformation of Power Relations: Collaborative Betterment and Collaborative Empowerment. American Journal of Community Psychology, 29(2), 277-284. https://doi.org/10.1023/A:1010 334831330 .

Hodges, S., Nesman, T., \& Hernandez, M. (1998). Promising practices: Building collaboration in systems of care. Vol. 6 . Washington, DC: Center for Effective Collaboration and Practice, American Institutes for Research.

Holwerda, A., Fokkens, A. S., Engbers, C., \& Brouwer, S. (2016). Collaboration between mental health and employment services to support employment of individuals with mental disorders. Disability and Rehabilitation, 38(13), 1250-1256. https://doi.org/10.3109/09638288.2015.1076075.

Holzer, H. J., \& Dunlop, E. (2013). Just the Facts, Ma'am: Postsecondary Education and Labor Market Outcomes in the U.S. (SSRN Scholarly Paper ID 2250297). IZA (Institute for the Study of Labor). https://papers.ssrn.com/abstract= 2250297.

Huxham, C. (1996). Creating Collaborative Advantage. Sage Publications.

Longoria, R. A. (2005). Is Inter-Organizational Collaboration Always a Good Thing. Journal of Sociology and Social Welfare, 32(3), 123-138.
McHugh, M. L. (2012). Interrater reliability: The kappa statistic. Biochemia Medica, 22(3), 276-282.

Miller, R., Sevak, P., \& Honeycutt, T. (n.d.). State Vocational Rehabilitation Agencies' Early Implementation Experiences with Pre-Employment Transition Services. In Mathematica Policy Research Reports (b158ab08ac3241fdb57cbfd13ccc03 e5; Mathematica Policy Research Reports). Mathematica Policy Research. Retrieved June 16, 2021, from https://ideas. repec.org/p/mpr/mprres/b158ab08ac3241fdb57cbfd13ccc 03e5.html.

Milward, H. B., Provan, K. G., Fish, A., Isett, K. R., \& Huang, K. (2010). Governance and collaboration: An evolutionary study of two mental health networks. Journal of Public Administration Research and Theory, 20(SUPPL. 1), i125-i141. https://doi.org/10.1093/jopart/mup038.

Morrissey, J. P., Calloway, M., Bartko, W. T., Ridgely, M. S., Goldman, H. H., \& Paulson, R. I. (1994). Local mental health authorities and service system change: Evidence from the Robert Wood Johnson program on chronic mental illness. The Milbank Quarterly, 72(1), 49-80.

Newman, L., Wagner, M., Knokey, A.-M., Marder, C., Nagle, K., Shaver, D., Wei, X., with Cameto, R., Contreras, E., Ferguson, K., Greene, S., and Schwarting, M. (2011). The Post-High School Outcomes of Young Adults With Disabilities up to 8 Years After High School. A Report From the National Longitudinal Transition Study-2 (NLTS2) (NCSER 2011-3005). Menlo Park, CA: SRI International.

Nicaise, P., Tulloch, S., Dubois, V., Matanov, A., Priebe, S., \& Lorant, V. (2013). Using social network analysis for assessing mental health and social services interorganisational collaboration: Findings in deprived areas in Brussels and London. Administration and Policy in Mental Health, 40(4), 331-339. https://doi.org/10.1007/s10488-0120423-y.

Noonan, P. M., McCall, Z. A., Zheng, C., \& Gaumer Erickson, A. S. (2012). An Analysis of Collaboration in a State-Level Interagency Transition Team. Career Development and Transition for Exceptional Individuals, 35(3), 143-154. https://doi.org/ $10.1177 / 2165143412443083$.

Nowell, B. (2009). Profiling Capacity for Coordination and Systems Change: The Relative Contribution of Stakeholder Relationships in Interorganizational Collaboratives. American Journal of Community Psychology, 44(3-4), 196-212. https://doi.org/10.1007/s10464-009-9276-2.

Rosenheck, R. A., Lam, J., Morrissey, J. P., Calloway, M. O., Stolar, M., \& Randolph, F. (2002). Service Systems Integration and Outcomes for Mentally Ill Homeless Persons in the ACCESS Program. Psychiatric Services, 53(8), 958-966. https://doi.org/10.1176/appi.ps.53.8.958.

Rosenheck, R., Morrissey, J., Lam, J., Calloway, M., Johnsen, M., Goldman, H., Randolph, F., Blasinsky, M., Fontana, A., Calsyn, R., \& Teague, G. (1998). Service system integration, access to services, and housing outcomes in a program for homeless persons with severe mental illness. American Journal of Public Health, 88(11), 1610-1615.

Rothbard, A. B., Min, S.-Y., Kuno, E., \& Wong, Y.-L. I. (2004). Long-term effectiveness of the ACCESS program in linking community mental health services to homeless persons with serious mental illness. The Journal of Behavioral Health Services \& Research, 31(4), 441-449. https://doi.org/10.1007/ BF02287695. 
Rupp, K., \& Scott, C. G. (1996). Trends in the characteristics of DI and SSI disability awardees and duration of program participation. Social Security Bulletin, 59(1), 3-21.

Social Security Administration. (2013). Supplemental Security Income (SSI) Recipients by Geographic Area, Sex, Eligibility, and Diagnostic Group, 2010 Data. Retrieved from: https://www.ssa.gov/policy/docs/data/ssi-2010/.

Swanson, S. J., Courtney, C. T., Meyer, R. H., \& Reeder, S. A. (2014). Strategies for integrated employment and mental health services. Psychiatric Rehabilitation Journal, 37(2), 86-89. https://doi.org/10.1037/prj0000049.

Trickett, E. J., Beehler, S., Deutsch, C., Green, L. W., Hawe, P., McLeroy, K., Miller, R. L., Rapkin, B. D., Schensul, J. J., Schulz, A. J., \& Trimble, J. E. (2011). Advancing the Science of Community-Level Interventions. American Journal of Public Health, 101(8), 1410-1419. https://doi.org/10.2105/ AJPH.2010.300113.
Tsasis, P. (2009). The social processes of interorganizational collaboration and conflict in nonprofit organizations. Nonprofit Management and Leadership, 20(1), 5-21. https://doi.org/ $10.1002 / \mathrm{nml} .238$.

Wagner, M. M. (1995). Outcomes for Youths with Serious Emotional Disturbance in Secondary School and Early Adulthood. The Future of Children, 5(2), 90-112. https://doi.org/10.2307/ 1602359

Wagner, M., \& Newman, L. (2012). Longitudinal transition outcomes of youth with emotional disturbances. Psychiatric Rehabilitation Journal, 35(3), 199-208. https://doi.org/ 10.2975/35.3.2012.199.208.

Weinstock, P., \& Barker, L. T. (1995). Mental health and vocational rehabilitation collaboration: Local strategies that work. Psychosocial Rehabilitation Journal, 18(4), 35-50. https:// doi.org/10.1037/h0095481. 